\title{
ESTABILIDADE FENOTÍPICA EM FEIJOEIRO ESTIMADA POR ANÁLISE AMMI COM GENÓTIPO SUPLEMENTAR ( $\left.{ }^{1}\right)$
}

\author{
JOÃO GUILHERME RIBEIRO GONÇALVES $\left({ }^{2,4}\right)$; ALISSON FERNANDO CHIORATO $\left({ }^{3}\right)$; \\ ELIANA FRANCISCHINELLI PERINA $\left({ }^{2}\right)$; SÉRGIO AUGUSTO MORAIS CARBONELL $\left({ }^{3,5^{*}}\right)$
}

\begin{abstract}
RESUMO
O presente trabalho teve por objetivo realizar a avaliação fenotípica de 19 linhagens e cultivares de feijoeiro, por meio da metodologia AMMI (Additive Main Effects and Multiplicative Interaction) com o uso do genótipo suplementar (GS), participantes dos ensaios de VCU 2005/2006/2007 para o Estado de São Paulo. O delineamento utilizado foi o de blocos casualizados, com três repetições e parcelas de quatro linhas de 4,0 m de comprimento, com as duas centrais como a parcela útil. A interação $\mathrm{G} \times \mathrm{A}$ foi altamente significativa, possibilitando a identificação de genótipos com maior estabilidade e adaptabilidade aos ambientes de cultivo envolvidos no estudo. Pela análise AMMI, evidenciaram-se como mais estáveis os genótipos: BRS-Grafite, LP 9979 e BRS-Pontal, para a época das águas; CV-48, IAC-Alvorada, IAC-Diplomata, LP 02-130, IAC-UNA e Gen 96A98-15-3-52-1, para a época da seca; BRS-Requinte, Z-28 e LP 01-38, para a época de inverno; e IAC-UNA, Z-28 e BRS-Grafite, para o conjunto das três épocas de semeadura. Para fins de recomendação, destacam-se como mais produtivos e promissores os genótipos LP 9979, BRS-Pontal, BRS-Requinte, LP 01-38 e Z-28. Os genótipos CV-48, IAC-Alvorada e IAC-UNA, referente à época da seca, aproximaram-se do genótipo suplementar, no entanto em relação ao conjunto das três épocas de semeadura não foram detectados genótipos próximos do GS.
\end{abstract}

Palavras-chave: Phaseolus vulgaris, feijão, interação G x A, adaptabilidade.

\section{ABSTRACT \\ PHENOTYPIC STABILITY IN COMMON BEAN ESTIMATED WITH SUPPLEMENTARY GENOTYPES}

The objective of this study was to evaluate the performance of the 19 lines and cultivars of common bean through AMMI (Additive Main Effects and Multiplicative Interaction) method, using supplementary genotypes (GS) in VCU trials of 2005/2006/2007 of São Paulo State. Random block design was used, with three replications per parcels of $4,0 \mathrm{~m}$ length each, the two centrals being the experimental useful one. $\mathrm{G} \times \mathrm{E}$ interaction was highly significant and allowed the identification of genotypes with greater stability and adaptability to the assayed environments. The genotypes 'BRS-Grafite', 'LP 9979' and 'BRS-Pontal' (rainy season), 'CV-48', 'IACAlvorada', 'IAC-Diplomata', 'LP 02-130', 'IAC-UNA' and 'Gen 96A98-15-3-52-1' (dry season), 'BRS-Requinte', 'Z-28' and 'LP 01-38' (winter season), 'IAC-UNA', 'Z-28' and 'BRS-Grafite' (joint seasons) were the most stable. Among these, 'LP 9979', 'BRS-Pontal', 'BRS-Requinte', 'LP 01-38' and 'Z-28' were the genotypes, with highest yield thus the most promising. 'CV-48', 'IAC-Alvorada' and 'IAC-UNA' genotypes were the closest to the supplementary genotype, in dry seasons. However, consider in seasons altogether no genotype was close to the supplementary genotype.

Key words: Phaseolus vulgaris, common bean, G x E interaction, adaptability.

(1) Recebido para publicação em 28 de fevereiro de 2008 e aceito em 14 de maio de 2009.

$\left(^{2}\right)$ Curso PG/IAC/APTA, Caixa Postal 28, 13012-970 Campinas (SP). E-mail: jgrgonalves@yahoo.com.br; efperina@yahoo.com.br.

$\left({ }^{3}\right)$ Centro de Grãos e Fibras, Instituto Agronômico, Caixa Postal 28, 13012-970 Campinas (SP). E-mail: afchiorato@iac.sp.gov.br; carbonel@iac.sp.gov.br ${ }^{(*)}$ Autor correspondente.

$\left({ }^{4}\right)$ Bolsa de Mestrado CAPES.

$\left({ }^{5}\right)$ Bolsista CNPq. 


\section{INTRODUÇÃO}

O feijão (Phaseolus vulgaris L.) juntamente com o arroz constitui a base da alimentação dos brasileiros, pois fornece ricas quantidades de proteína vegetal e carboidratos (FACHINI et al., 2006). Os grandes produtores de feijão são os Estados do Paraná, Minas Gerais, Bahia, Santa Catarina e São Paulo. No Estado de São Paulo é cultivado em três épocas de acordo com o zoneamento agroecológico da cultura, com semeaduras efetuadas em agosto-setembro (águas), janeiro-fevereiro (seca) e abril-maio (inverno) (PInZAN et al., 1994).

De acordo com a CONAB (2007), a área total semeada no Brasil é de 4.168 .300 ha, com produção de 3.508 .100 toneladas e rendimento médio de $842 \mathrm{~kg}$ $\mathrm{ha}^{-1}$, sendo este considerado baixo principalmente em relação ao potencial de produção da espécie, que em condições adequadas é superior a $3.500 \mathrm{~kg} \mathrm{ha}^{-1}$.

Para a realização de uma correta recomendação de novas cultivares devem-se fazer estudos sobre a interação genótipo $x$ ambiente $(G \times$ A) que se caracteriza pelo efeito diferencial dos ambientes sobre os genótipos. Por meio da realização de experimentos em vários locais e anos pode-se estimar com maior precisão os efeitos desta interação (CRUZ, 2006) ou auxiliar o melhorista na seleção de genótipos adaptados e responsivos a determinadas condições ambientais. De acordo com Costa et al. (1999) e Cruz e Regazzi (2001), o termo adaptabilidade refere-se à capacidade de os genótipos aproveitarem vantajosamente o estímulo do ambiente, enquanto estabilidade refere-se à capacidade de os genótipos desempenharem um comportamento altamente previsível em função do estímulo do ambiente.

As análises de adaptabilidade e estabilidade são procedimentos estatísticos que permitem a identificação dos genótipos mais estáveis e adaptados, isto é, que podem responder de forma previsível às variações do ambiente. Existem inúmeros métodos para se estimar esses parâmetros de adaptabilidade e estabilidade na avaliação de linhagens superiores. Conforme Duarte e Vencovsky (1999), o método AMMI (Additive Main Effect and Multiplicative Interaction) destaca-se por ter sido desenvolvido com a proposta de melhor descrever a interação $G \times A$, mediante o descarte de ruídos adicionais, presentes nas estimativas tradicionais da interação.

Para ZoBel et al. (1988), este método permite uma análise mais detalhada da interação $G \times A$, garante a seleção de genótipos mais produtivos, propicia estimativas mais precisas das respostas genotípicas e possibilita fácil interpretação gráfica dos resultados da análise estatística.
Estudando a estabilidade e adaptabilidade de linhagens de feijoeiro pelos métodos AMMI e DPM (Desvios da Produtividade Máxima), CARbonell et al. (2004) chegaram à conclusão que estes métodos produziram resultados congruentes em relação à estabilidade. Também relatam que o método DPM possui procedimento simples além de fácil interpretação dos resultados, e as linhagens consideradas estáveis foram também as mais produtivas. Já o método AMMI forneceu informações sobre a estabilidade e adaptabilidade das linhagens em um único gráfico denominado biplot, que por sua vez é uma das vantagens do método por facilitar a interpretação (inspeção visual) e também por permitir a identificação de genótipos adaptados a ambientes específicos.

Neste contexto, o presente trabalho teve como objetivo realizar a avaliação fenotípica de 19 genótipos de feijoeiro dos grupos comerciais Carioca e Preto, pertencentes aos ensaios de VCU 2005/2006/2007 do Estado de São Paulo, por meio da análise AMMI com uso do genótipo suplementar.

\section{MATERIAL E MÉTODOS}

Foram avaliados 19 genótipos de feijoeiro, dos grupos comerciais Carioca e Preto pertencentes aos ensaios de VCU (Valor de Cultivo e Uso) realizados em 2005/2006/2007 no Estado de São Paulo (Tabela 1).

Os ensaios foram semeados em 24 ambientes (Tabela 2), com semeaduras realizadas na época das águas, da seca e de inverno, conforme o zoneamento agroecológico da cultura (PInZAN et al., 1994).

As cultivares IAC-Carioca Tybatã e Pérola, do grupo Carioca, e, IAC-UNA e FTNobre, do grupo Preto, foram utilizadas como testemunhas para a avaliação da produtividade e nos estudos de estabilidade. Foi utilizado o teste de Dunett, a 5\% de probabilidade, para a comparação das médias entre genótipos do mesmo grupo de cor.

Os ensaios foram delineados em blocos casualizados, com três repetições de parcelas, contendo quatro linhas de $4,0 \mathrm{~m}$ de comprimento conforme preconizam as normas do MAPA/RNC (2007) para ensaios de VCU de feijoeiro, no Estado de São Paulo. O espaçamento entre linhas foi o de $0,5 \mathrm{~m}$ com 10 a 12 plantas viáveis por metro e área útil da parcela correspondendo às duas linhas centrais $\left(4,0 \mathrm{~m}^{2}\right)$. 
Foram realizadas as análises de variância para cada ensaio, a fim de avaliar a variabilidade genética entre os tratamentos e a precisão experimental. Posteriormente, foram realizadas as análises conjuntas de variância, descartando-se os ensaios com coeficiente de variação superior a $25 \%$, conforme determinam as normas do MAPA/RNC (2007). Para avaliar a homogeneidade das variâncias residuais utilizou-se o teste de Hartley $\left(\mathrm{F}_{\text {máx }}\right)$ (RAMALHO et al., 2000) e, quando necessário, foram feitos ajustes nos graus de liberdade pelo método de Cochran (1954) apud Pimentel-Gomes (2000). As interpretações quanto às significâncias do teste $\mathrm{F}$ foram realizadas somente após estes ajustes.
As análises de estabilidade e adaptabilidade foram realizadas pelo modelo AMMI (Additive Main Effects and Multiplicative Interaction Analysis). Essa análise é uma combinação de métodos univariados (análise de variância) com métodos multivariados (análise de componentes principais e decomposição de valores singulares). A análise AMMI (Zobel et al.,1988) combina em um único modelo, componentes aditivos para os efeitos principais de genótipos $\left(\mathrm{g}_{\mathrm{i}}\right)$ e de ambientes $\left(a_{\mathrm{j}}\right)$, e componentes multiplicativos para os efeitos da interação $\left(g a_{i j}\right)$ (DuARte e VencovsKY, 1999).

Tabela 1. Cultivares e linhagens de feijoeiro dos grupos comerciais Carioca e Preto pertencentes aos ensaios de VCU desenvolvidos em 2005/2006/2007 no Estado de São Paulo

\begin{tabular}{|c|c|c|}
\hline Cultivares e Linhagens de Feijoeiro & Tipo de grão & Instituição \\
\hline 1-IAC-Carioca Tybatã & Carioca - testemunha & IAC \\
\hline 2- Pérola & Carioca - testemunha & EMBRAPA \\
\hline 3- IAC-UNA & Preto - testemunha & IAC \\
\hline 4- FT-Nobre & Preto - testemunha & FT \\
\hline 5- IAC-Alvorada & Carioca & IAC \\
\hline 6- Gen 96A45-3-51-52-1 & Carioca & IAC \\
\hline 7- Gen 96A98-15-3-52-1 & Carioca & IAC \\
\hline 8- Gen 96A3-P1-1-1 & Preto & IAC \\
\hline 9- IAC-Diplomata & Preto & IAC \\
\hline 10- LP 9979 & Carioca & IAPAR \\
\hline 11- LP 01-38 & Carioca & IAPAR \\
\hline 12- LP 98-122 & Preto & IAPAR \\
\hline 13-LP 02-130 & Preto & IAPAR \\
\hline 14- BRS-Requinte & Carioca & EMBRAPA \\
\hline 15- BRS-Pontal & Carioca & EMBRAPA \\
\hline 16- BRS-Supremo & Preto & EMBRAPA \\
\hline 17- BRS-Grafite & Preto & EMBRAPA \\
\hline 18- CV-48 & Carioca & UFLA \\
\hline 19- Z-28 & Carioca & UFLA \\
\hline
\end{tabular}

IAC = Instituto Agronômico. FT = FT- Pesquisa e Sementes. IAPAR = Instituto Agronômico do Paraná. EMBRAPA = Empresa Brasileira de Pesquisa Agropecuária. UFLA = Universidade Federal de Lavras.

Tabela 2. Ambientes utilizados para a implantação dos ensaios de VCU desenvolvidos em 2005/2006/2007, nas respectivas épocas de semeadura

\begin{tabular}{|c|c|c|c|c|c|}
\hline Águas/2005 & Águas/2006 & Seca/2006 & Seca / 2007 & Inverno/2006 & Inverno/2007 \\
\hline A- Capão Bonito & E- Holambra II & J- Mococa & O- Avaré & R- Fernandópolis & V- Mococa \\
\hline B- Monte Alegre do Sul & F- Avaré & K- Avaré & P- Tatuí & S- Ribeirão Preto & X-Araras \\
\hline C- Mococa & G- Mococa & $\begin{array}{l}\text { L- Espírito Santo } \\
\text { do Pinhal }\end{array}$ & $\begin{array}{l}\text { Q- Monte } \\
\text { Alegre do Sul }\end{array}$ & T- Votuporanga & Z- Colina \\
\hline D- Tatuí & $\begin{array}{l}\text { H- Capão Bonito } \\
\text { I- Itaberá }\end{array}$ & $\begin{array}{l}\text { M- Tatuí } \\
\text { N- Capão Bonito }\end{array}$ & & U- Colina & \\
\hline
\end{tabular}


No modelo proposto, além dos termos convencionais de um modelo de análise conjunta de variância, como média geral, efeito de genótipos, efeito de ambiente e erro experimental conforme descrevem DuARTE e Vencovsky (1999), os demais termos resultam da análise de componentes principais aplicada a matriz de interações:

$$
\mathbf{G A}_{(\mathrm{ga})}=\left[\hat{(\text { ga })_{\mathrm{ij}}}\right], \text { sendo }(\hat{\mathrm{gaa}})_{\mathrm{ij}}=\mathbf{Y}_{\mathrm{ij}}-\overline{\mathbf{Y}}_{\mathrm{i} .}-\overline{\mathbf{Y}}_{. \mathrm{j}}+\overline{\mathbf{Y}}_{. .}
$$

No modelo desta análise tem-se que:

$\mathbf{Y}_{\mathrm{ij}}=\boldsymbol{\mu}+\mathbf{g}_{\mathrm{i}}+\mathbf{a}_{\mathrm{j}}+\sum_{\mathrm{k}=1}^{\mathrm{n}} \boldsymbol{\lambda}_{\mathbf{k}} \gamma_{\mathrm{ik}} \boldsymbol{\alpha}_{\mathrm{jk}}+\boldsymbol{\rho}_{\mathrm{ij}}+\overline{\boldsymbol{\varepsilon}}_{\mathrm{ij}}$, em que: ambiente $\mathrm{j}$;

$\mathrm{Y}_{\mathrm{ij}}$ : é a resposta média do genótipo i no

$\mu$ : é a média geral das respostas;

$\mathrm{g}_{\mathrm{i}}$ : é o efeito fixo do genótipo i $(\mathrm{i}=1,2, \ldots . \mathrm{g})$;

$a_{j}$ : é o efeito fixo do ambiente $j(j=1,2, \ldots a)$;

$\lambda_{\mathrm{k}}$ : é o k-ésimo valor singular de GA (escalar);

$\gamma_{\text {ik }}$ : é o elemento correspondente ao i-ésimo genótipo no vetor singular $\gamma_{\mathrm{k}}$ (vetor singular coluna);

$\alpha_{\mathrm{jk}}$ : é o elemento correspondente ao j-ésimo ambiente no vetor $\alpha_{k}$ (vetor singular linha);

$\rho_{\mathrm{ij}}$ : é o resíduo da ACP presente na SQ da interação G x A (porção ruído);

$\bar{\varepsilon}_{\mathrm{ij}}$ : é o erro experimental médio, assumido independentemente;

$\mathrm{k}$ : índice que se refere aos eixos principais da $\mathrm{ACP}$ aplicada à matriz GA. Logo, $k=1,2, \ldots, p$, sendo $p$ o posto da matriz GA, onde: $p=$ mínimo entre $(\mathrm{g}-1) \mathrm{e}$ $(\mathrm{a}-1)$;

n: é o número de eixos ou componentes principais selecionados para descrever o padrão da interação $\mathrm{G}$ x A.

A soma de quadrados associada à interação $\mathrm{G} \times \mathrm{A}$ original $\left(\mathrm{SQ}_{\mathrm{GxA}}\right)$ é particionada em $\mathrm{n}$ eixos singulares ou componentes principais que vão descrever a porção padrão da interação. A porção denominada ruído é descartada, o que melhora a capacidade preditiva do modelo. Cada eixo corresponde a um modelo AMMI, da família de modelos possíveis (Duarte e Vencovsky, 1999). A seleção do modelo que melhor descreve a interação foi realizada pelo teste $\mathrm{F}$ de Gollob (1968) e pelo teste $\mathrm{F}_{\mathrm{r}}$ de Cornelius et al. (1992) apud (Piepho, 1995). Após a seleção, realizou-se o estudo de estabilidade e adaptabilidade, por meio de gráficos biplot, derivados da própria análise. Os gráficos descrevem a porção padrão da interação GxA, mostrando os genótipos e ambientes que menos contribuem para essa interação e também permitem identificar as adaptações específicas existentes entre os genótipos e ambientes.
Como forma de incrementar a análise foi inserido nas avaliações um genótipo suplementar (GS), com base no método de LiN e BinNs (1988). O propósito da representação de um ponto adicional no gráfico (GS) é fazer comparações dos genótipos avaliados com o genótipo de referência, definido com base em critérios de interesse do pesquisador. Podese assumir que esse genótipo simula uma testemunha de adaptação produtiva ótima relativamente ao conjunto avaliado e, portanto, de elevada estabilidade agronômica. Assim, em um gráfico biplot, a distância entre os pontos correspondentes a um genótipo avaliado e o genótipo suplementar fornece uma medida da adaptabilidade e estabilidade produtiva do genótipo real, de acordo com este conceito. A representação gráfica constituindo elementos suplementares deve ser construída, mantendo-se os posicionamentos relativos dos indivíduos e das variáveis reais (PACHECO, 2004).

A interpretação da estabilidade no biplot AMMI foi realizada a partir da distância dos pontos representativos dos genótipos e ambientes ao escore zero. Assim, esses pontos que pouco contribuem para a interação apresentam menor distância, indicando maior estabilidade. Serão também considerados estáveis agronomicamente os genótipos que se aproximarem do genótipo suplementar (PACHECO et al., 2005).

Para a realização da análise foi utilizada uma rotina em linguagem SAS/IML, com adaptações ao programa disponibilizado por DUARTE e VENCOVSKY (1999).

\section{RESULTADOS E DISCUSSÃO}

Os efeitos da interação $G \times A$, o efeito de ambientes e o efeito de genótipos foram significativos pelo teste $\mathrm{F}$ a $1 \%$ e $5 \%$ de probabilidade, para todas as épocas de semeadura analisadas. Esses resultados são indicativos da interação $\mathrm{G} \times \mathrm{A}$, dificultando de certa forma, a identificação de genótipos estáveis para a produtividade em função das regiões utilizadas para as avaliações. Deste modo, torna-se necessário um estudo mais detalhado em relação à interação $G \times A$, proporcionado pelas análises de estabilidade e adaptabilidade.

Pela metodologia AMMI, foi possível decompor a matriz de interações $G$ x A para o conjunto de ensaios da época das águas, em oito componentes principais (posto da matriz G x A - \{[min (19-1);(9-1)] $=8\})$. Pelo teste Fr de Cornelius, os cinco primeiros eixos são significativos $(p<0,001)$, levando assim à seleção do modelo AMMI5 (Tabela 3). Esses cinco primeiros eixos (IPCA1 a IPCA5) acumularam $89,0 \%$ da $\mathrm{SQ}_{\mathrm{GxA}}$. 


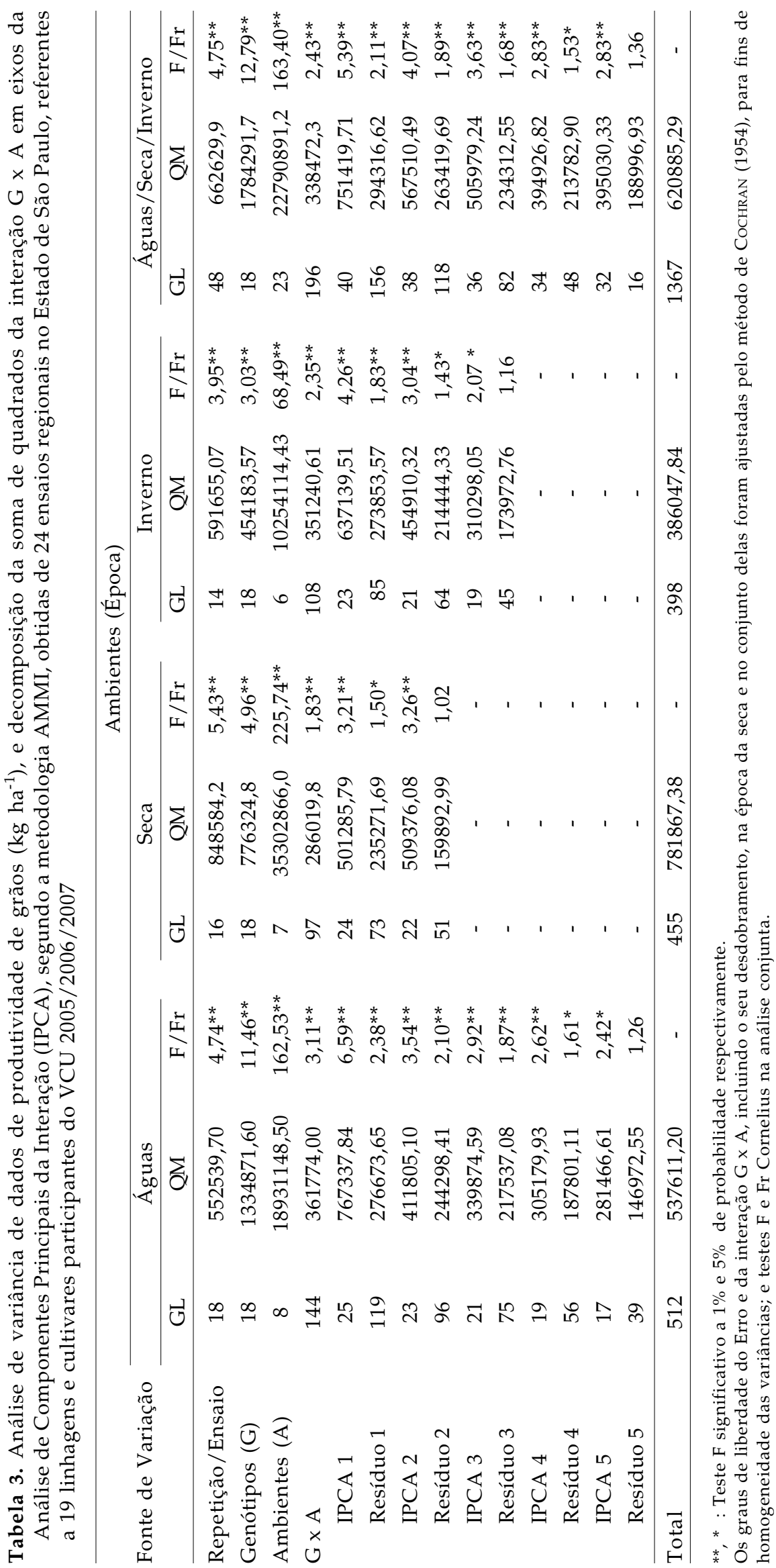


Essa parcela significativa da variação associada a $\mathrm{SQ}_{\mathrm{GxA}}$ é denominada de porção padrão. No entanto, os gráficos biplot foram elaborados utilizando os primeiros eixos, ou seja, modelo AMMI3, conforme CARBONELL et al. (2004), embora poderiam ser produzidos e aproveitados em qualquer dimensão. Deve-se ressaltar que a análise AMMI não se restringe apenas à representação gráfica (facilidade de visualização), podendo ser também interpretada a partir das estimativas de interações de genótipos com ambientes e pela matriz de médias preditas fornecidas pela análise. $\mathrm{O}$ primeiro eixo principal de interação capturou $36,8 \%$, o segundo, $18,2 \%$ e o terceiro eixo, $13,7 \%$, totalizando uma porcentagem de $68,7 \%$ da $\mathrm{SQ}_{\mathrm{GxA}}$, denominada de porção padrão, cujo restante $31,3 \%$ correspondeu à porção ruído. Os gráficos biplot resultantes da análise de modelo AMMI3 foram feitos utilizando-se a combinação dos eixos principais, dois a dois, IPCA1 x IPCA2 e IPCA1 x IPCA3.

De acordo com as figuras 1 e 2, pode-se observar, para a época das águas, que os genótipos que menos contribuíram com a interação $\mathrm{G} \times \mathrm{A}$, conforme as combinações de eixos principais no biplot AMMI, ou seja, os estáveis para produtividade de grãos foram: BRSGrafite (17), LP 9979 (10) e BRS-Pontal (15). Esses genótipos revelaram produtividade média de $2.833 \mathrm{~kg} \mathrm{ha}^{-1}, 3.138$ $\mathrm{kg} \mathrm{ha}^{-1}$ e $3.085 \mathrm{~kg} \mathrm{ha}^{-1}$ respectivamente. Assim, os genótipos LP 9979 (10) e BRS-Pontal (15) são os mais promissores, pois sua média de produção foi superior a $3.000 \mathrm{~kg} \mathrm{ha}^{-1}$. Já os genótipos Pérola (2), LP 98-122 (12) e Gen 96A98-15-3-52-1 (7) foram os que mais contribuíram para a interação $\mathrm{G} \times \mathrm{A}$, pelos maiores escores no eixo da interação. Nenhum genótipo aproximou-se geometricamente do Genótipo Suplementar (GS), nos referidos gráficos.

Pode-se também observar por meio das figuras 1 e 2 que o genótipo FT-Nobre (4) foi especificamente adaptado ao ambiente de Monte Alegre do Sul (B), e os genótipos Gen 96A3-P1-1-1 (8), Gen 96A98-15-352-1 (7) e BRS-Pontal (15) adaptaram-se aos ambientes de Avaré (F) e Itaberá (I).

Em relação à época da seca, a soma de quadrados da interação $G \times A$ foi decomposta em sete componentes principais. Por meio do teste Fr de Cornelius, os dois primeiros eixos foram significativos $(p<0,001)$, levando à seleção do modelo AMMI2 (Tabela 3). Assim o gráfico biplot foi elaborado com os dois primeiros eixos, ou seja, IPCA1 e IPCA2. O primeiro eixo principal de interação (IPCA1) capturou $33,4 \%$ da $\mathrm{SQ}_{\mathrm{GxA}}$ e o IPCA2, 31,1\%, tendo acumulado uma porcentagem de $64,5 \%$ da $\mathrm{SQ}_{\mathrm{GxA}}$. Esta porcentagem foi considerada o padrão da interação GxA, para esse conjunto de ensaios, já o restante $(35,5 \%)$ correspondeu à porção ruído, ainda presente na $\mathrm{SQ}_{\mathrm{GxA}}$.

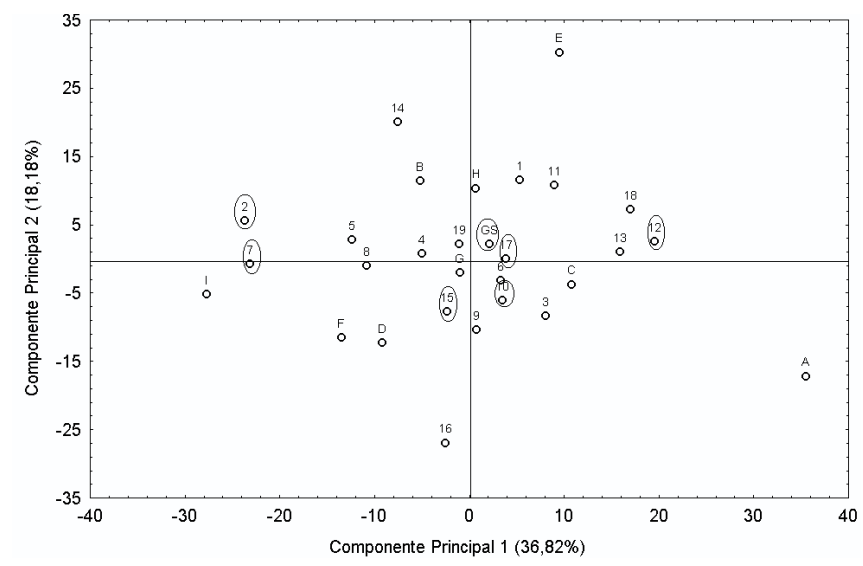

Figura 1. Gráfico biplot de modelo AMMI3, para dados de produtividade de grãos de feijoeiro de tegumento carioca e preto referente à época das águas, avaliados nas safras de 2005/2006, em nove ambientes (IPCA1 x IPCA2).

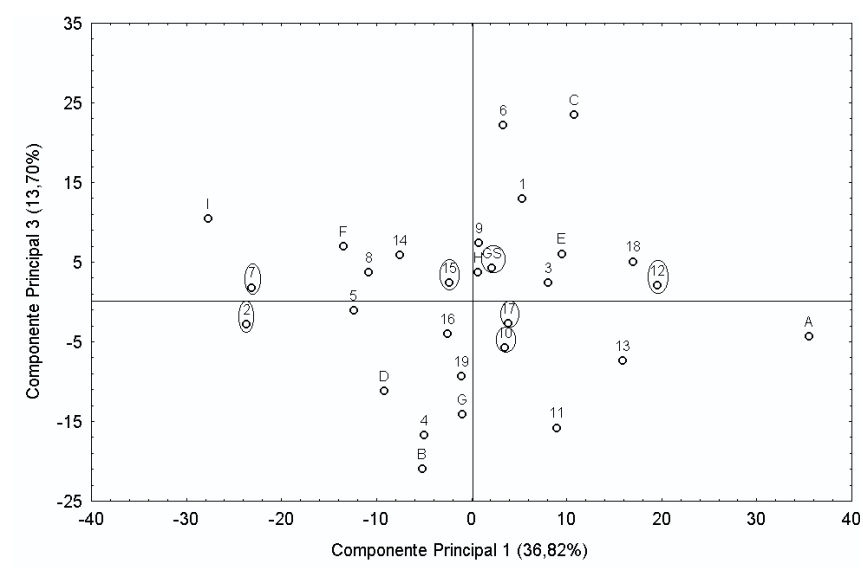

Figura 2. Gráfico biplot de modelo AMMI3, para dados de produtividade de grãos de feijoeiro de tegumento carioca e preto referente à época das águas, avaliados nas safras de 2005/2006, em nove ambientes (IPCA1 x IPCA3).

Analisando a figura 3, pode-se observar que os genótipos que mais contribuíram com a interação G x A foram: Gen 96A45-3-51-52-1 (6), BRS-Pontal (15) e BRS-Requinte (14), pelos maiores valores de escores nos referidos eixos, em relação aos outros genótipos envolvidos no estudo. Os genótipos que menos contribuíram, ou seja, os mais estáveis são aqueles com escores próximos de zero no biplot, isto é: CV-48 (18), IAC-Alvorada (5), IAC-Diplomata (9), LP 02-130 (13), IAC-UNA (3) e Gen 96A98-15-3-52-1 (7). Os genótipos CV-48 (18), IAC-Alvorada (5) e IAC-UNA (3) ficaram próximos do Genótipo Suplementar (GS), destacando-se dos demais por suas características agronômicas desejáveis e padrão de interação similar ao de um suposto genótipo (GS) que reúne as máximas produtividades observadas em cada ambiente. O genótipo IAC-Alvorada (5) se destaca 
pelo fato de ser estável, produtivo e possuir ótima qualidade de grãos (grãos mais cheios, mais claros, resistentes ao escurecimento e teor de proteína médio de $22 \%$ ).

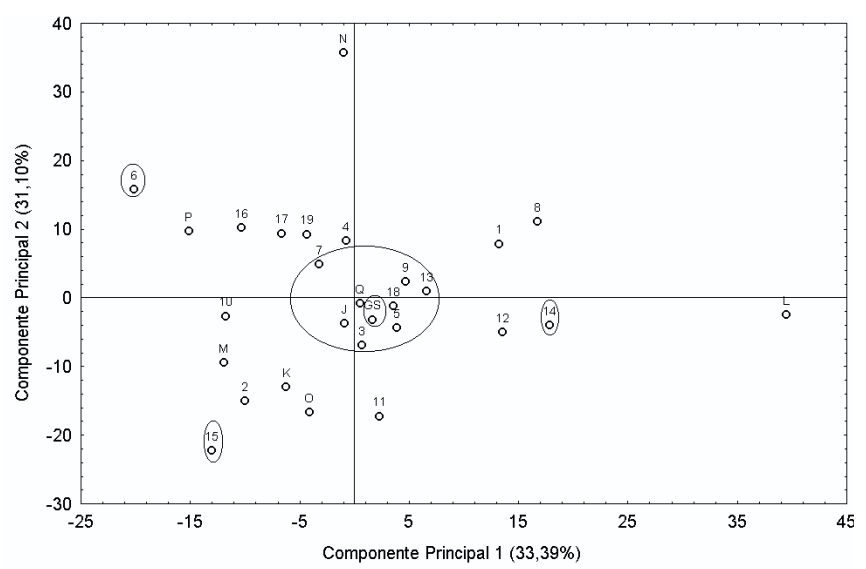

Figura 3. Gráfico biplot de modelo AMMI2, para dados de produtividade de grãos de feijoeiro de tegumento carioca e preto referente à época da seca, avaliados nas safras de 2006/2007, em oito ambientes (IPCA1 x IPCA2).

Os genótipos IAC-Alvorada (5), CV-48 (18), IAC-UNA (3), LP 01-38 (11), LP 98-122 (12) e BRSRequinte (14), conforme se observa na figura 3, adaptaram-se aos ambientes de Monte Alegre do Sul (Q) e Espírito Santo do Pinhal (L); os genótipos BRSSupremo (16), Gen 96A45-3-51-52-1 (6), BRS-Grafite (17), Z-28 (19), Gen 96A98-15-3-52-1 (7) e FT-Nobre (4) aos ambientes de Tatuí (P) e Capão Bonito (N); e os genótipos Pérola (2), LP 9979 (10) e BRS-Pontal (15), aos ambientes de Avaré (K), Avaré (O) e Tatuí (M).

Os ambientes de cultivo mais estáveis (próximos ao eixo zero) foram: Mococa (J) e Monte Alegre do Sul (Q), com produtividades médias de 2.018 $\mathrm{kg} \mathrm{ha}^{-1} \mathrm{e} 2.202 \mathrm{~kg} \mathrm{ha}^{-1}$ respectivamente. Já os ambientes em que houve as maiores produtividades em relação a esta época de cultivo foram: Avaré (K) e Avaré $(\mathrm{O})$, ou seja, $4.065 \mathrm{~kg} \mathrm{ha}^{-1} \mathrm{e} 3.461 \mathrm{~kg} \mathrm{ha}^{-1}$ respectivamente.

Para a época de inverno de acordo com o teste Fr de Cornelius os três primeiros eixos foram significativos $(p<0,001)$, com respectivo resíduo não significativo (Tabela 3), o que levou à seleção do modelo AMMI3. Os gráficos biplot seguiram as combinações de eixos principais, tomados dois a dois, como seguem: IPCA1 x IPCA2 e IPCA1 x IPCA3. O modelo AMMI3 acumulou $79,4 \%$ da $\mathrm{SQ}_{\mathrm{GxA}}$, o que correspondeu à porção padrão da interação $G \times A$ para esse conjunto de ensaios, e os outros $20,6 \%$ da $\mathrm{SQ}_{\mathrm{GxA}}$ corresponderam à porção ruído.
Nas figuras 4 e 5, observam-se os genótipos BRS-Requinte (14), Z-28 (19) e LP 01-38 (11) como os mais estáveis, pois foram os que menos contribuíram para a $S_{G_{x A}}$. Observa-se também que nenhum genótipo ficou próximo do genótipo suplementar (GS). Os genótipos Pérola (2) e CV-48 (18) foram os que mais contribuíram para a $\mathrm{SQ}_{\mathrm{GxA}}$, uma vez que possuíam elevados escores nos eixos IPCA. Pode-se também observar algumas adaptações específicas, ou seja, os genótipos IAC-Diplomata (9), Pérola (2) e Z-28 (19), ao ambiente de Fernandópolis (R) e os genótipos Gen 96A45-3-51-52-1 (6) e BRS-Requinte (14) aos ambientes de Mococa (V) e Colina (Z).

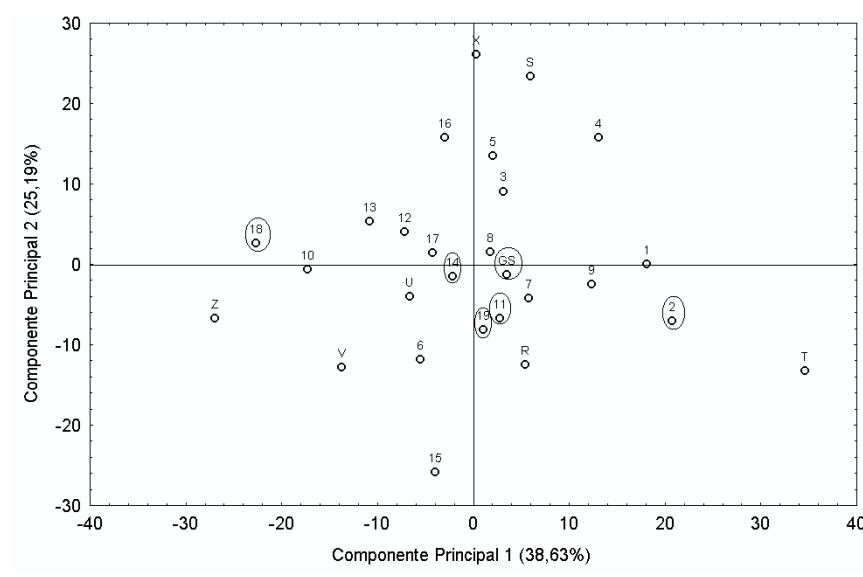

Figura 4. Gráfico biplot de modelo AMMI3, para dados de produtividade de grãos de feijoeiro de tegumento carioca e preto referente à época de inverno, avaliados nas safras de 2006/2007, em sete ambientes (IPCA1 x IPCA2).

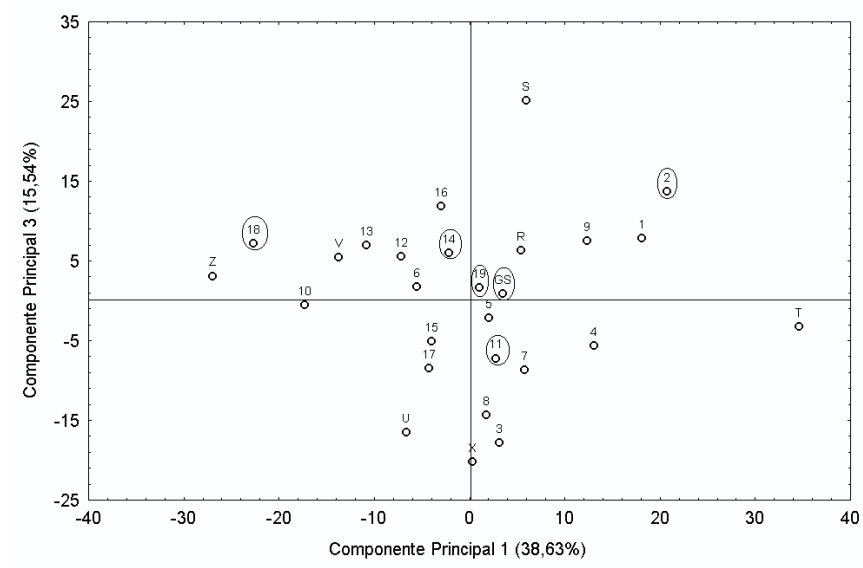

Figura 5. Gráfico biplot de modelo AMMI3, para dados de produtividade de grãos de feijoeiro de tegumento carioca e preto referente à época de inverno, avaliados nas safras de 2006/2007, em sete ambientes (IPCA1 x IPCA3). 
Considerando-se conjuntamente as três épocas de semeadura, a análise AMMI decompôs a matriz da interação G x A em 18 componentes principais. Pelo teste Fr de Cornelius, os cinco primeiros eixos foram significativos $(\mathrm{p}<0,001)$, levando à seleção do modelo AMMI5 (Tabela 3). Esses cinco primeiros eixos (IPCA1 a IPCA5) acumularam $68,4 \%$ da $\mathrm{SQ}_{\mathrm{GxA}}$. Apesar disso, os gráficos biplot foram elaborados utilizando os três primeiros eixos, pelas mesmas razões comentadas anteriormente para a época de semeadura das águas. Pode-se observar que o primeiro eixo principal de interação (IPCA1) capturou $21,4 \%$ da $\mathrm{SQ}_{\mathrm{GxA}}$ o segundo (IPCA2), 15,4\% e o terceiro (IPCA3), 13,0\% da SQ $\mathrm{GxA}_{\text {, }}$ acumulando-se os três, $49,8 \%$, que correspondeu à porção padrão nesse conjunto de dados e o restante $(50,2 \%)$ foi atribuído à porção ruído.

Nas figuras 6 e 7, pode-se observar que os genótipos e ambientes mais estáveis ou que menos contribuíram para a interação $\mathrm{G}$ x A (com menores escores nos eixos IPCA) foram a cultivar padrão IACUNA (3) e as linhagens Z-28 (19) e BRS-Grafite (17), e os ambientes de Monte Alegre do Sul (B), Mococa (V) e Mococa (J). Já os genótipos e ambientes que tiveram os maiores escores IPCA, isto é, os que mais contribuíram para a interação foram: genótipos - CV-48 (18), Pérola (2) e Gen 96A98-15-3-52-1 (7), e ambientes - Capão Bonito (A) e Votuporanga (T).

Para este conjunto das três épocas de cultivo, pode-se observar que os genótipos Gen 96A45-3-5152-1 (6), LP 9979 (10), BRS-Grafite (17) e BRS-Supremo (16) adaptaram-se especificamente aos ambientes de Mococa (C), Tatuí (D) e Tatuí (P); os genótipos LP 98122 (12), IAC-UNA (3), LP 01-38 (11) e CV-48 (18) aos ambientes de Mococa (J), Holambra (E) e Colina (Z); o genótipo FT-Nobre (4) aos ambientes de Araras (X) e Ribeirão Preto (S) e o genótipo BRS-Requinte (14) ao ambiente de Espírito Santo do Pinhal (L).

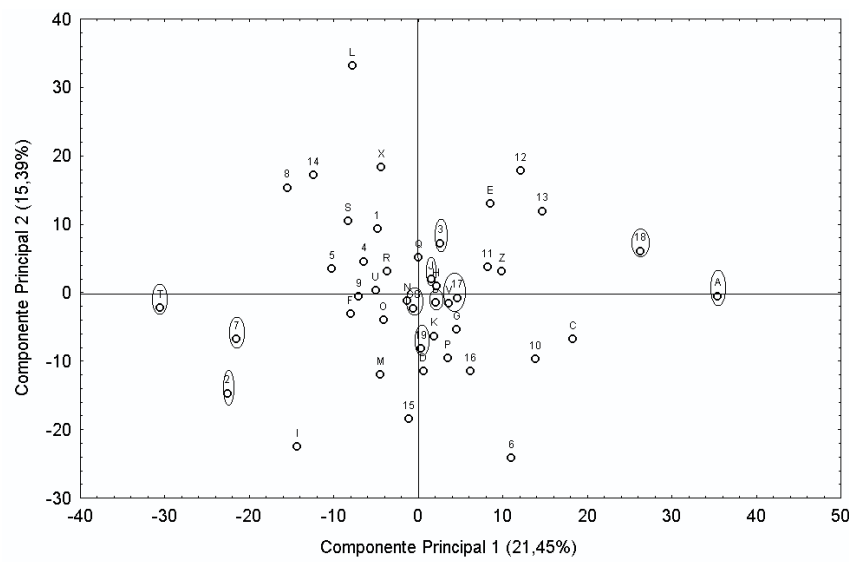

Figura 6. Gráfico biplot de modelo AMMI3, para dados de produtividade de grãos de feijoeiro de tegumento carioca e preto referente às três épocas de semeadura, avaliados nas safras de 2005/2006/2007, em 24 ambientes (IPCA1 x IPCA2).

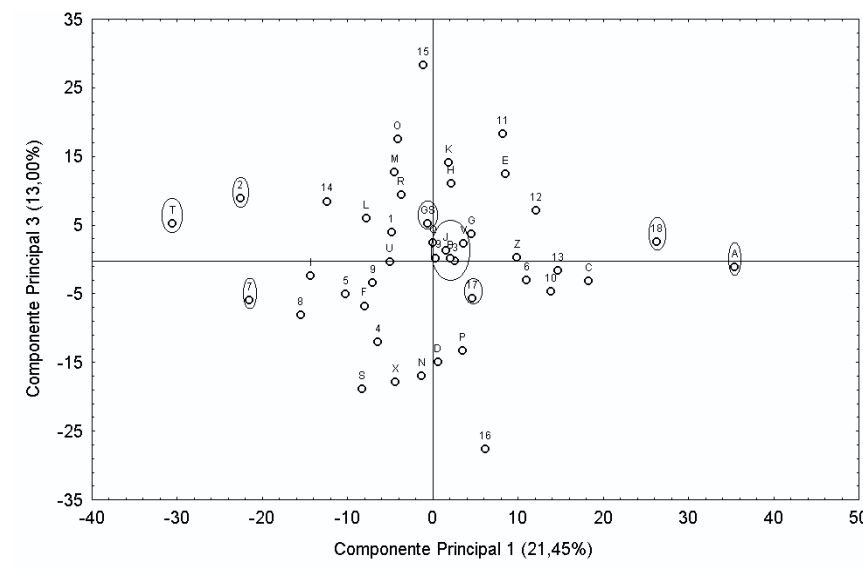

Figura 7. Gráfico biplot de modelo AMMI3, para dados de produtividade de grãos de feijoeiro de tegumento carioca e preto referente às três épocas de semeadura, avaliados nas safras de 2005/2006/2007, em 24 ambientes (IPCA1 x IPCA3).

\section{CONCLUSÕES}

1. Para o conjunto das três épocas de semeadura, os genótipos estáveis são IAC-UNA, Z-28 e BRS-Grafite.

2. Em relação a cada época de cultivo, os genótipos estáveis em relação à época das águas são: BRS-Grafite, LP 9979 e BRS-Pontal; para a época da seca: CV-48, IAC-Alvorada, IAC-Diplomata, LP 02-130, IAC-UNA e Gen 96A98-15-3-52-1; e para a época de inverno: os genótipos BRS-Requinte, Z-28 e LP 01-38.

3. Entre os genótipos citados acima, destacamse LP 9979, BRS-Pontal, BRS-Requinte, LP 01-38 e Z-28, devido à estabilidade e aos rendimentos médios elevados.

4. Os genótipos CV-48, IAC-Alvorada e IACUNA, em relação à época da seca, ficaram próximos do Genótipo Suplementar.

\section{AGRADECIMENTOS}

À CAPES pela concessão da bolsa de estudo; à FAPESP e ao CNPq, pelo apoio financeiro ao Programa de Melhoramento do Feijoeiro, do Instituto Agronômico - IAC; às estações experimentais do IAC e aos estagiários. Ao Professor João Batista Duarte (Universidade Federal de Goiás) e à pesquisadora Lizz Kezzy de Morais, pelo auxílio com a análise AMMI.

\section{REFERÊNCIAS}

CARBONELL, S.A.M.; AZEVEDO FILHO J.A.A.; DIAS L.A. S.; GARCIA A.A.F.; MORAIS L.K. Common bean cultivars and lines interaction with environments. Scientia Agrícola, v.61, p.169-177, 2004. 
CONAB - COMPANHIA NACIONAL DE ABASTECIMENTO, Disponível em: http//:www.conab.gov.br, Acesso em: 1. ${ }^{\circ}$ agosto 2007.

COSTA, J.G.; MARINHO, J.T.S.; PEREIRA, R.C.A.; LEDO, F.J.S.; MORAES, R.N.S. Adaptabilidade e estabilidade de produção de cultivares de milho recomendadas para o Estado do Acre. Ciência e Agrotecnologia, v.23, p.7-11, 1999.

CRUZ, C.D. Programa GENES: Biometria. Viçosa: UFV, , 2006. p.109-112.

CRUZ, C.D.; REGAZZI, A.J. Modelos biométricos aplicados ao melhoramento genético. Viçosa: UFV, 2001. 390p.

DUARTE, J.B.; VENCOVSKY, R. Interação genótipos $\mathbf{x}$ ambientes: uma introdução à análise AMMI. Ribeirão Preto: Sociedade Brasileira de Genética, 1999. 60p.

FACHINI, C.; BARROS, V.L.N.P.; RAMOS JUNIOR, E.U.; ITO, M.A.; CASTRO, J.L. Importância do feijão no agronegócio brasileiro. In: DIA DE CAMPO DE FEIJÃO, 22., 2006, Capão Bonito. Resumos... Campinas: Instituto Agronômico, 2006. p.1-7.

GOLLOB, H.F.A. Statistical model which combines features of factor analytic and analysis of variance techniques. Psychometrika, v.33, p.73-115, 1968.

LIN, C.S.; BINNS, M.R. A superiority measure of cultivar performance for cultivar $\mathrm{x}$ location data. Canadian Journal of Plant Science, v.68, p.193-198, 1988.

MAPA/RNC - Ministério da Agricultura, Pecuária e Abastecimento/Registro Nacional de Cultivares. Anexo IV Requisitos mínimos para determinação do valor de cultivo e uso de feijão (Phaseolus vulgaris) para a inscrição no registro nacional de cultivares - RNC, 2007.

PACHECO, R.M. Estratificação de ambientes em cerrados do Brasil Central para fins de seleção e recomendação de cultivares de soja. 2004. 173p. Tese (Doutorado). Escola de Agronomia e Engenharia de Alimentos, Universidade Federal de Goiás, Goiânia.

PACHECO, R.M.; DUARTE, J.B.; VENCOVSKY, R.; PINHEIRO, J.B.; OLIVEIRA, A.B. Use of supplementary genotypes in AMMI analysis. Theoretical and Applied Genetics, v.110, p.812-818, 2005.

PIEPHO, H.P. Robustness of statistical test for multiplicative terms in the additive main effects and multiplicative interaction model for cultivar trial. Theoretical Applied of Genetics, v.90, p.438-443, 1995.

PIMENTEL-GOMES, F. Curso de estatística experimental. Piracicaba: ESALQ, 2000. 477p.

PINZAN, N.R.; BULISANI, E.A.; BERTI, A.J. Feijão: Zoneamento ecológico e épocas de semeadura para o Estado de São Paulo. Campinas: CATI, 1994, 19p. (Boletim Técnico 218)

RAMALHO, M.A.P.; FERREIRA, D.F.; OLIVEIRA, A.C. Experimentação em genética e melhoramento de plantas. Lavras: UFLA, 2000. 326p.

ZOBEL, R.W.; WRIGHT, M.J.; GAUCH, H.G. Statistical analysis of a yield trial. Agronomy Journal, v.80, p.388-393, 1988. 